\title{
A rare case report on ovotesticular disorders of sex development (DSD) 46XY variant
}

\section{Sujata Swain*, Lopamudra Pradhan, R. N. Satpathy, P. C. Mahapatra}

Department of Obstetrics \& Gynaecology, S.C.B. Medical College, Cuttack, Odisha, India

Received: 29 October 2014

Accepted: 10 November 2014

\author{
*Correspondence: \\ Dr. Sujata Swain, \\ E-mail: sjt_swain@yahoo.co.in,drsujata74@gmail.com
}

Copyright: (c) the author(s), publisher and licensee Medip Academy. This is an open-access article distributed under the terms of the Creative Commons Attribution Non-Commercial License, which permits unrestricted non-commercial use, distribution, and reproduction in any medium, provided the original work is properly cited.

\begin{abstract}
Ovotestis refers to the histology of a gonad that contains both ovarian follicles and testicular tubular elements. Ovotesticular DSD is a rare condition characterized by mixed ovarian and testicular tissue. Majority have a 46,XX karyotype, 7\% have 46,XY karyotype and 10-40\% exhibit chromosomal mosaicism. Here, we report the case of a boy with a 46,XY karyotype diagnosed as ovotesticular DSD by gonadal biopsy. A 14 year-old reared as boy presented with came with ambiguous genitalia with no palpable gonads since birth and developed progressive virilization and gynaecomastia at puberty having curved phallus with glans, redundant prepucial skin, labia majora and hypoplastic labia minora, rudimentary vagina with small introitus was present. External urethral meatus present lower down the vestibular area above the introitus. Testicles not felt. USG - revealed definite uterus behind Urinary bladder with small intraabdominal testes. Karyotyping - 46XY Barr body present. Diagnostic laparoscopy showed Uterus with bilateral fallopian tubes. Bilateral gonadectomy done. Histopathologic examination report revealed bilateral gonadoblastoma in testis and ovotestis. Patient underwent transperitoneal excision of Mullerian remnants. Patient was discharged with an advice of cap testosterone undecanoate and regular follow up. We highlight the importance of histological and cytogenetic investigation in DSD.
\end{abstract}

Keywords: Ambiguous genitalia, Ovotesticular DSD, Streak gonad, Gonadoblastoma

\section{INTRODUCTION}

Ovotesticular DSD [previously known as (True hermaphroditism)] is characterized by presence of ovarian and testicular tissues in the same individual. Majority have a 46,XX karyotype, $7 \%$ have $46, \mathrm{XY}$ karyotype and 10-40\% exhibit chromosomal mosaicism.

Many patients with ovotesticular disorder of sexual development have a uterus. Müllerian duct structures typically develop on the gonad side(s) not containing testicular tissue. The gonads may be ovotestis, or they may be a combination of an ovary on one side and a testis or ovotestis on the other.

OT-DSD are born with ambiguous genitalia. Most affected individuals are reared as males due to the size of the phallus. Most have varying degrees of labioscrotal fusion and/or hypospadias. A diagnosis of OT-DSD is based solely on the presence of ovarian and testicular tissue in the gonad and not on the characteristics of the internal and external genitalia, even if ambiguous.

\section{CASE REPORT}

A 14 year old patient reared as a male presented with ambiguous genitalia with no palpable gonads since birth. He developed progressive virilization and gynaecomastia at puberty. Born out of non-consanguineous marriage at term by vaginal delivery without any neonatal complications. There is no history of maternal virilization during pregnancy or prenatal exposure to androgenic drugs. There is no family history of previously affected relatives or unexplained infant death. 


\section{On general examination}

Patient has height $-142 \mathrm{~cm}$, weight - $45 \mathrm{~kg}$ with no abnormality detected in general examination. Cardiovascular system, respiratory system were normal. Abdomen was soft with no palpable mass.

On examination of secondary sexual characters: bilateral breasts enlarged, Pubic and axillary hairs dense, presence of chest hairs, receding of forehead hair, facial hairs were present, moustache small hairs on either side of midline, beard was absent.

On examination of external genitalia: Curved phallus with glans $(5 \mathrm{~cm})$ with redundant preputial skin present. Labia majora and hypoplastic labia minora with rudimentary vagina and urethral meatus above the introitus present. Gonads were not palpable neither in the inguinal region nor in the inguinoscrotal region.

\section{Investigations}

USG Abdomen and Pelvis: Uterus $5.5 \times 2.3 \mathrm{~cm}$, endometrium and myometrium differentiated, ovaries not visualized. A small thick walled cystic structure $(5 \mathrm{~cm} \mathrm{x}$ $2.5 \mathrm{~cm}$ ) with lobulated outline present in the pelvis with tiny peripheral reflection foci possibly intra-abdominal testes.

CECT abdomen and pelvis: small hypodense lesion in right inguinal canal possibly testes.

17 hydroxy progesterone (17OHP) level: normal

Serum free testosterone $-0.03 \mathrm{ng} / \mathrm{ml}$,

LH - $26.68 \mathrm{mIU} / \mathrm{ml}$,

FSH - $44.31 \mathrm{mIU} / \mathrm{ml}$,

LDH - $306 \mathrm{U} / \mathrm{L}$,

Beta hCG - $1.2 \mathrm{mIU} / \mathrm{ml}$,

AFP - $0.5 \mathrm{IU} / \mathrm{ml}$

Serum electrolytes normal,

Karyotyping: 46XY,

Diagnostic laparoscopy was done to confirm the diagnosis and to take biopsy.

Laparoscopy - Mullerian structures were present with rudimentary uterus with bilateral tubes present.

There was right side solid mass of size $4 \mathrm{~cm} \mathrm{x} 4 \mathrm{~cm}$ with left side streak gonad.
Bilateral gonadectomy was done.

Histopathology report - revealed left streak gonad with testicular gonadoblastoma with intratubular germ cell neoplasia and

Right gonad with gonadoblastoma in a ovotestis showing lobules of cells having large round nuclei without nucleoli and mitosis with vacuolated cytoplasm, smaller granulosa cells and call exner bodies, irregular foci of calcification.

Transperitoneal excision of Mullerian remnants (Uterus with fallopian tube and fatty lump around the deep inguinal ring) was done in next sittings .Histopathology report shows normal uterus with endometrium and myometrium, fallopian tubes, cervical tissue and epididymal canals enclosed by loose stroma.

Patient was discharged with hormonal therapy (Testosterone undecanoate capsules) $80 \mathrm{mg}$ once daily for one month. Follow up hormonal tests shows testosterone level of - $566.4 \mathrm{ng} / \mathrm{dl}$ (normal range in adults - 260 to 1000). Patient will be followed up with LDH, AFP, HCG levels. Reconstructive surgery has been planned.

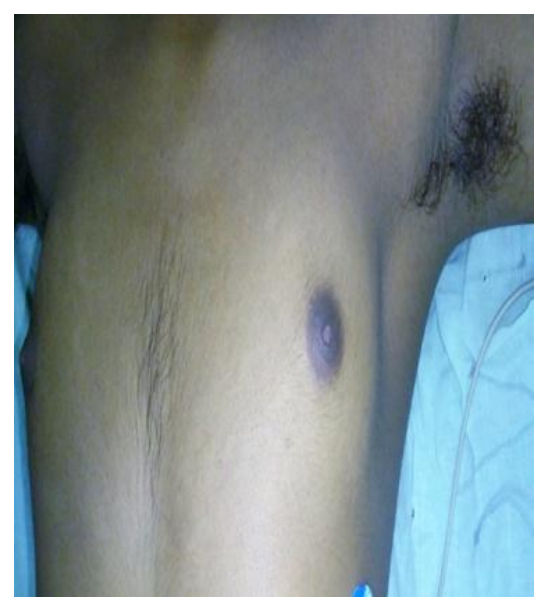

Figure 1: Gynaecomastia.
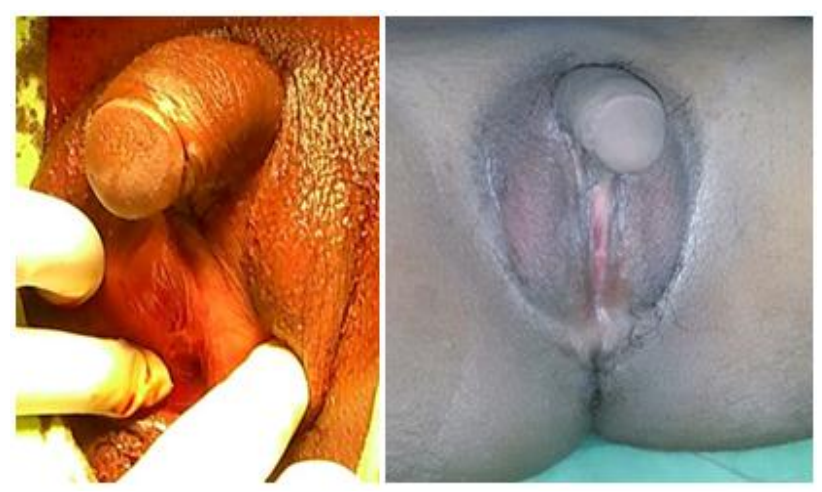

Figure 2: External genitalia. 


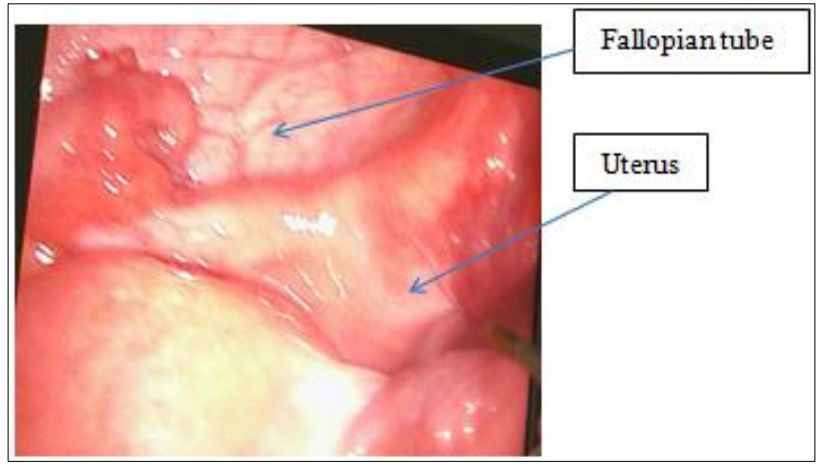

Figure 3: Mullerian structures were present (rudimentary uterus with bilateral tubes present).

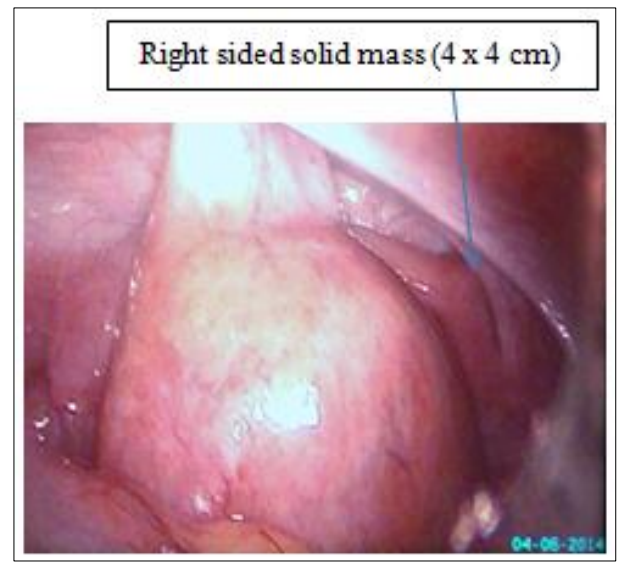

Figure 4: Right sided solid mass.

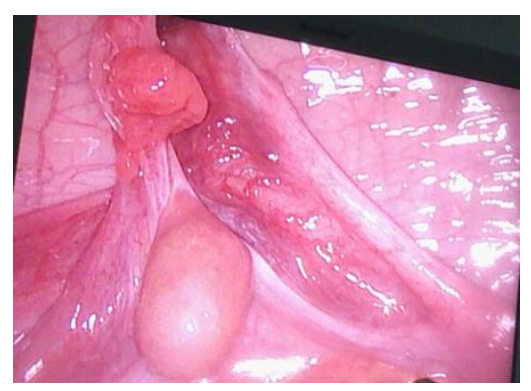

Figure 5: Left sided streak gonad.

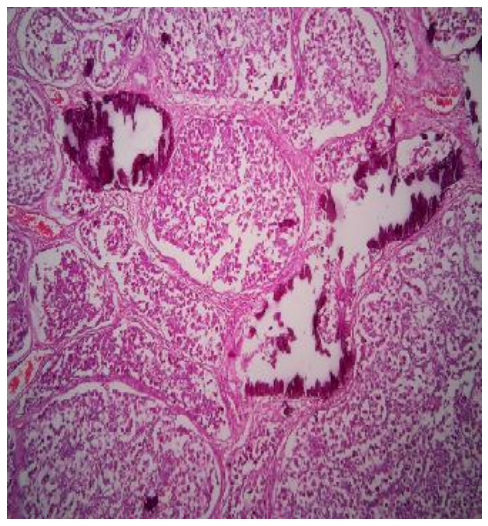

Figure 6: Left streak gonad.

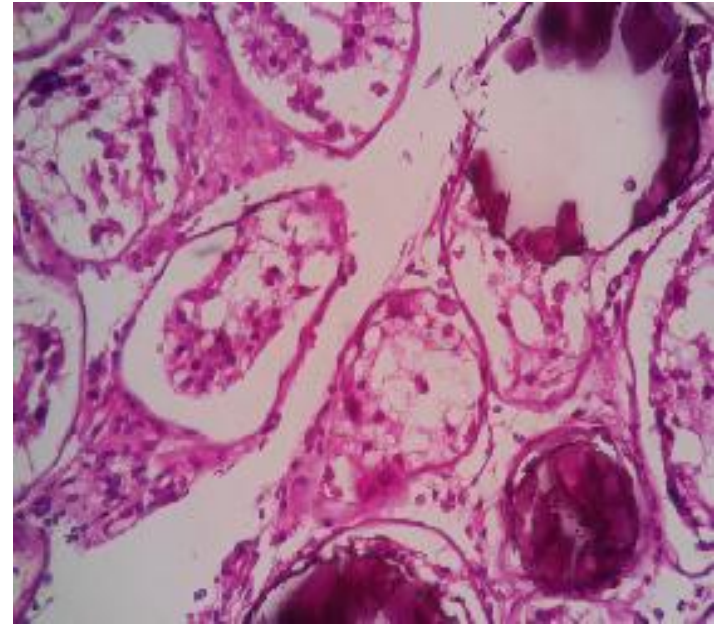

Figure 7: Testicular gonadoblastoma with intratubular germ cell neoplasia.

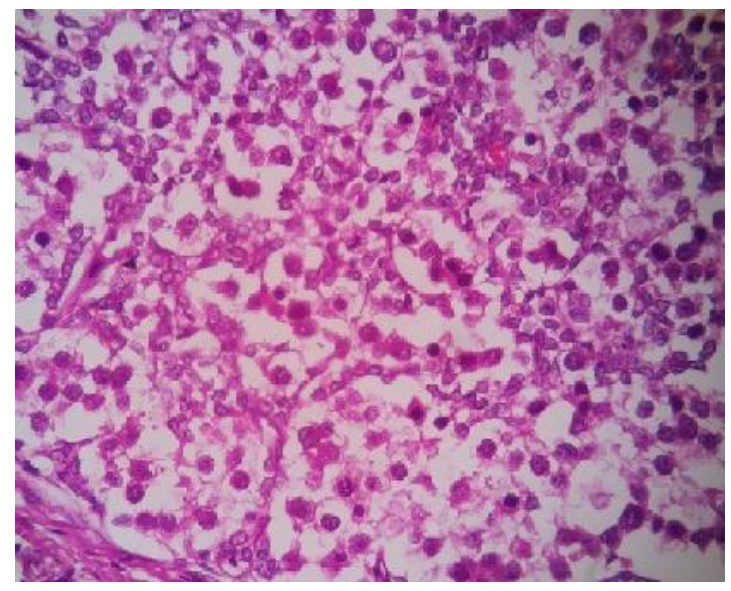

Figure 8: Right gonad with gonadoblastoma in a ovotestis.

\section{DISCUSSION}

The term 'Disorders Of Sex Development' (DSD) is now proposed to define congenital conditions in which a dysharmony between chromosomal, gonadal and anatomical sex exists. ${ }^{1}$

Genital ambiguity occurs in 1 in 4500 births, and ovotesticular disorder of sexual development occurs in fewer than $10 \%$ of all disorders of sexual development. More than 400 cases have been reported worldwide. ${ }^{2}$

In infancy the gonads appear to have normal ovarian tissue with numerous follicles and normal testicular tissue with seminiferous tubules containing germ cells. However, as time passes the ovarian tissue usually becomes functional and the testicular tissue regresses, becoming dysgenetic and showing interstitial fibrosis and lack of spermogonia. ${ }^{3,4}$

Besides the presence of ovotestis, ovary and testis may be found separately. ${ }^{3}$ Ovarian tissue is most often found on the left side and testicular tissue on the right side. ${ }^{3}$ 
There may be a mixture of Müllerian and Wolffian derivatives; in most patients uterus or unicornus uterus is observed. The external genitalia are ambiguous with various degrees of virilization, while, rarely, normal female genitalia may be present.,

Laparoscopy or laparotomy with gonadal biopsy/gonadectomy allows for histologic confirmation of both ovarian and testicular tissue. Conservative gonadal surgery is the procedure of choice for individuals with ovotesticular disorder of sexual development. ${ }^{7}$ Prophylactic gonadectomy should be considered in those who manifest signs of virilization or are at an increased risk of gonadal malignancy.Clitoral recession, vaginoplasty, and labioscrotal reduction are necessary for people with ovotesticular disorder of sexual development who are given a female sex assignment. Masculinizing genitoplasty consists of correction of the penile curvature and repositioning of the urethral meatus. Gonadal tumors with malignant potential occur in $2.6 \%$ of all cases of ovotesticular disorder of sexual development. The testis or testicular component of an ovotestis is likely to be dysgenetic; dysgerminomas, seminomas, gonadoblastomas, and yolk sac carcinomas have all been reported. Those with the 46,XY karyotype are at the greatest risk of developing a gonadal malignancy. A new born infant born with ambiguous external genitalia presents a major diagnostic challenge and a social and medical emergency. Once the diagnosis of genital ambiguity is made, on-going psychological support for the patient, parents, and other family members is critical. ${ }^{8}$

Evaluation should be made efficiently to ensure that the appropriate gender is assigned, potential life threatening complications are recognized, necessary medical, surgical and psychological interventions begin promptly.

Funding: No funding sources Conflict of interest: None declared Ethical approval: Not required

\section{REFERENCES}

1. Hughes IA, Houk C, Ahmed SF, Lee PA, LWPES Consensus Group, ESPE Consensus Group. Consensus statement on management of intersex disorders. Arch Dis Child. 2006;91:554-63.

2. Josso N, Audi L, Shaw G. Regional variations in the management of testicular or ovotesticular disorders of sex development. Sex Dev. 2011;5(5):225-34.

3. Krob G, Braun A, Kuhnle U. True hermaphroditism: geographical distribution, clinical findings, chromosomes and gonadal histology. Eur J Paediatr. 1994;153:2-10.

4. Verkauskas G, Jaubert F, Lortat-Jacob S, Malan V, Thibaud E, Nihoul F. The long-term follow up of 33 cases of true hermaphroditism: a 40-year experience with conservative gonadal surgery. J Urol. 2007;177:726-31.

5. Hadjiathanasiou CG, Brauner R, Lortat-Jacob S, Nivot S, Jaubert F, Fellous $M$, et al. True hermaphroditism: genetic variants and clinical management. J Paediatr. 1994;125:738-44.

6. Damiani D, Fellous M, McElreavey K, Barbaux S, Barreto ES, Dichtchekenian V, et al. True hermaphroditism: clinical aspects and molecular studies in 16 cases. Eur J Endocrinol. 1997;136: 2014.

7. Verkauskas G, Jaubert F, Lortat-Jacob S, Malan V, Thibaud E, Nihoul-Fékété C. The long-term followup of 33 cases of true hermaphroditism: a 40-year experience with conservative gonadal surgery. J Urol. 2007 Feb;177(2):726-31.

8. Matsui F, Shimada K, Matsumoto F, Itesako T, Nara $\mathrm{K}$, Ida S, et al. Long-term outcome of ovotesticular disorder of sex development: a single center experience. Int J Urol. 2011 Mar;18(3):231-6.

DOI: $10.5455 / 2320-1770 . i j r \operatorname{cog} 20141263$

Cite this article as: Swain S, Pradhan L, Satpathy

RN, Mahapatra PC. A rare case report on ovotesticular disorders of sex development (DSD) 46XY variant. Int J Reprod Contracept Obstet Gynecol 2014;3:1163-6. 